\title{
EFFECT OF DIODE LASER IRRADIATION ON THE BOND STRENGTH OF FIBER POSTS AFTER ENDODONTIC RETREATMENT USING DIFFERENT SEALERS
}

\author{
Amira Mohamed Elsharkawy*
}

\begin{abstract}
Purpose: To investigate the effect of diode laser activated irrigation on bond strength between fiber post and radicular dentin after endodontic retreatment using two different sealers.

Materials and Methods: Seventy-two extracted human maxillary central incisors were collected, decoronated, endodontically prepared then divided to three groups $(n=24)$ according to sealer type: GP group: gutta-percha without sealer (control group); AD group: AD sealer; and $\mathrm{BC}$ group: Bioceramic sealer. Specimens were endodontically retreated after 30 days using the same sealers. $10 \mathrm{~mm}$ deep post spaces were prepared in each specimen. Each group was further sub-divided into three subgroups $(\mathrm{n}=8)$ according to post space treatment: irrigated with saline (Control), (EDTA) and (laser and EDTA). One tooth from each group was selected for SEM analysis. Posts were cemented, push out tests were performed. Failure modes were analyzed using a digital microscope.
\end{abstract}

Results: With all dentin pretreatment protocols, $\mathrm{AD}$ group recorded the highest bond strength mean value followed by GP and BC group respectively, with significant difference $(\mathrm{P}<0.05)$ as demonstrated by two-way ANOVA. However, (Laser+EDTA) recorded the highest bond strength followed by (EDTA) and (saline) respectively, with significant difference as demonstrated by three-way ANOVA $(\mathrm{P}<0.05)$. There was no-significant difference among root regions $(\mathrm{P}>0.05)$. Predominant failure mode was the mixed type as detected by Chi square test. SEM revealed absence of smear layer and opened dentinal tubules after (laser and EDTA) treatment.

Conclusions: laser activated irrigation of root dentin significantly improved the bond strength of fiber post after endodontic retreatment with both sealers.

KEY WORDS: Laser \# fiber post \# retreatment \# Bioceramic sealer.

\footnotetext{
* Associate Professor, Fixed Prosthodontics, Faculty of Dentistry, $6^{\text {th }}$ of October University, Giza, Egypt
} 


\section{INTRODUCTION}

Endodontically treated teeth are frequently restored with fiber post and resin luting cement. Fiber posts are characterized by good esthetics and similar modulus of elasticity similar to dentin, so improving stress distribution of functional loads to the root canal..$^{(1)}$ One of the major problems of fiber posts is dislodgement from the root canal. Resin cements can produce a mono-block with root canal walls. Therefore, success of a fiber post depends on proper bond of post to root dentin. ${ }^{(2)}$ Previous studies $(2,3,4)$ found that endodontic retreatment resulted in an adverse effect on fiber post push out bond strength compared to endodontic treatment. Pereira et al ${ }^{(2)}$ found that endodontic retreatment negatively affected the adhesive resin cement penetration and consequently the fiber post bond strength. The inaction of the drills and solvents used to eradicate the root filling material yields a new smear layer rich in sealer and gutta-percha remnants plasticized by the frictional heat, can occlude dentinal tubules. $(3,4)$

Recently, resinous sealers are commonly used, having the ability to penetrate lateral canals, and dentinal tubules. These obstructed dentinal tubules, interfere with the formation of a hybrid layer of resin cement ,subsequently, reducing the post bond strength..$^{(5)}$ Bengoa et al ${ }^{(6)}$ confirmed the importance of endodontic sealer assessment before using in a tooth that will be restored with a fiber post.

Bioceramic sealers are becoming popular owing to their ability to bond to dentin surface and formation of hydroxyapatite. Bioceramic sealers are bioactive, biocompatible, radiopaque, hydrophilic, have dimensional stability, an alkaline $\mathrm{pH}$, and antibacterial effect. Moreover, these sealers use the moisture of dentinal tubules to initiate and accomplish their setting reactions. This explains the recent reports about difficult complete removal of calcium-based sealers using rotary techniques. ${ }^{(7)}$

Different adhesive systems are available for the fiber post cementation. Self-adhesive resin cements were introduced in the market to simplify the cementation process. Self-adhesive cement's adhesion mechanism is established on micromechanical retention and chemical interaction between monomer acidic groups and hydroxyapatite. According to the manufacturer, phosphoric acid molecule in a methacrylate group will react with the calcium ions of the hard dental tissues, consequently the cement infiltrate the smear layer and tooth structure. The interface between the cement and the dentin could be compromised by thick smear layer of gutta percha and sealer created along the canal walls during endodontic retreatment. ${ }^{\left({ }^{(8)}\right.}$

Several techniques have been proposed to remove endodontic filling materials, including the use of endodontic hand files, rotary systems, ultrasonic, laser, heat and the use of adjunctive solvents. (9) Among these chemical solvents that are used as irrigants during the biomechanical preparation; ethylene diamine tetra acetic acid (EDTA) chelates calcium ions and promotes dentin demineralization and smear layer removal. ${ }^{(10)}$

Recently, ultrasonic systems (11) and laser procedures ${ }^{(12)}$ are extensively used for root canal cleanings. The use of these techniques for irrigation activation is an extra method for smear layer removal from root canals. Among the new trends in the laser field is the diode laser device with a wave length emission at $980 \mathrm{~nm}$, it has shown to be a highly effective and reliable method in endodontic treatment due to its antimicrobial effect compared to the high intensity lasers. ${ }^{(13)}$

In fact, there is no established retreatment protocol that confirms complete removal of these materials and the smear layer from radicular dentin. Controversies exist regarding whether additional dentin treatment before post cementation using diode laser activated irrigation could improve sealer removal in retreatment cases. ${ }^{(14)}$

So the aim of the present study was to investigate 
the effect of diode laser activated irradiation on bond strength between fiber post and radicular dentin after endodontic retreatment using bioceramic or epoxybased sealer. The null hypotheses were: 1) there would be no difference in bond strength of fiber post after laser activated irrigation after retreatment using bioceramic or epoxy-based sealer. 2) There would be no difference in the push out bond strength between both sealers used.

\section{MATERIALS AND METHODS}

\section{Sample Size Calculation}

Based on previous research ${ }^{(15)}$ sample size of 7 in each group has a $80 \%$ power to detect a difference between means of 4.04 with a significance level (alpha) of 0.05 (two-tailed) and 95\% confidence intervals. In $80 \%$ (the power) of those experiments, the $\mathrm{P}$ value will be less than 0.05 (two-tailed) so the results will be deemed "statistically significant". In the remaining $20 \%$ of the experiments, the difference between means will be deemed "not statistically significant". Report created by GraphPad StatMate 2.00 .

Specimen preparation: Seventy- two freshly extracted non-carious human maxillary central incisors were collected from oral surgery department in Faculty of dentistry; Cairo University. Teeth were chosen free from cracks, fractures, internal resorption. Calculus and soft tissues were removed from the teeth. All teeth were stored in saline solution. Teeth were decoronated $2 \mathrm{~mm}$ above the CEJ using (Isomet 1000; Buehler, Lake Bluff, IL, USA). All root canal preparations were completed by the same operator. Working length was predicted visually $1 \mathrm{~mm}$ shorter from the apical foramen.

Protaper universal rotary system (Dentsply, Maillefer, Ballaigues, Switzerland) was used Cleaning and shaping using the crown down technique in the following order: S1 and S2 are shaping files used in a brushing motion then the finishing files F1, F2, F3 up to finishing F4 file (size 40 with $6 \%$ apical taper) using X smart plus endomotor (Dentsply, Maillefer, Ballaigues, Switzerland). Torque and speed were fixed according to the manufacturer instructions $(2 \mathrm{~N} /$ $\mathrm{cm}$ torque and a constant speed of $300 \mathrm{rpm}$ ). Irrigation was done during treatment first by $5 \mathrm{ml}$ $2.5 \%$ sodium hypochlorite for one minute followed by $5 \mathrm{ml} 17 \%$ EDTA ( PREVEST DentPro, India) for one minute then a final flush with saline for 1 min. Paper points (Dentsply, Maillefer) were used for root canal drying before obturation. Specimens were randomly divided in to three groups of 24 specimens each $(n=24)$ according to the sealer used during obturation:

GP Group (n=24): Gutta percha without sealer (control).

AD Group ( $n=24)$ : AD Seal (ADSEAL Meta, biomed, Korea).

BC Group (n=24): Bio-C Sealer (BIOC) (Angelus, Londrina, Brazil).

The root canals were obturated with gutta-percha F4 (Dentsply, Maillefer, Ballaigues, Switzerland) using lateral compaction technique. Then the root canal orifices were sealed using flowable composite (Polofil NHT flow, Voco, Germany). The teeth were kept in saline solution for 30 days, until retreatment.

Endodontic Retreatment: Using ProTaper Universal rotary retreatment files, the root canals of the three groups underwent retreatment. Using a \#2 Gates-Glidden drills (MANI Inc., Tochi-gi, Japan), $3 \mathrm{~mm}$ of the coronal parts of the root canal walls was removed. Three drops of chloroform (Merck, Darmstadt, Germany) were dropped inside each root canal. D1, D2 and D3 files were used for the removal of the coronal, middle and apical thirds of the root canal up to the working length, respectively. Apical patency was maintained by the use of no\#15 C+ (Rogin, Dental, Korea) manual file then F1, F2 and F3 finishing files were used for 
the final apical preparation. All the steps of similar irrigation, drying and obturation of the root canals for each group were repeated as those of the initial endodontic treatment, using the same sealers. The root canal orifices were sealed using flowable composite (Charmcore, Dentkist, Korea). Teeth were stored for two weeks in saline solution at room temperature to allow complete sealer setting.

Post space preparation: All specimens were then fixed in self-cured cylindrical acrylic blocks (consuming cylinder block former) using a surveyor to ensure orientation in the long axis of the root. First, the flowable composite were removed with high speed hand piece and round bur. Then the Gutta percha were removed with Gates Glidden drills \#3 to \#4 (Dentsply, Maillefer) for 10- mm depth, maintaining $3 \mathrm{~mm}-4 \mathrm{~mm}$ of guttapercha as an apical seal. After this procedure, the post spaces were prepared to a depth of $10 \mathrm{~mm}$ with special preparation drills included in post kit corresponding to the post size (GLASSIX plus, Nordin, Switzerland), using a low speed hand piece (Sirona, Germany) attached to bench drilling machine. Using $5 \mathrm{ml}$ of saline solution to irrigate the canal during and after drilling. Followed by post spaces drying using paper points.

Each group was further sub-divided into three subgroups of eight specimens each $(\mathrm{n}=8)$ according to post space treatment before post cementation; all irrigations were done by the needle gauge no.30 to penetrate to the apical third of the post space:

Saline (control): Each canal was irrigated using saline for $1 \mathrm{~min}$. and then dried using paper points.

EDTA: Each canal was irrigated using 17\% EDTA solution (PREVEST DentPro, India) for one minute, and then canals were irrigated with saline then dried using paper points.

EDTA+laser: the Diode laser beam ( Wiser, Doctor Smile, LAMBADA SpA- Italy) emitting at $980 \mathrm{~nm}$ operating in pulsed mode was used for the activation of the $5 \mathrm{ml}$ EDTA solution, which was repeatedly injected in the canal by a 30 -gauge needle. During the irrigation, the $300 \mu \mathrm{m}$ radial optical fiber was inserted into the entire extension of the post space and irradiated from apical to cervical axis in spiral movements at a ratio of $2 \mathrm{~mm} / \mathrm{second}$. Five cycles of irradiation with 20 seconds time intervals between cycles were performed permitting root cooling between the cycles. The average power density of the laser at $\mathrm{CW}$ was $2.5 \mathrm{~W} / \mathrm{cm}^{2}$. A useful duty cycle of 50\% (50/50 msec activated/ deactivated) was set to pulsed mode with an average power density of $994 \mathrm{~W} / \mathrm{cm}^{2}{ }^{(16,17)}$

TABLE (1): Samples grouping:

\begin{tabular}{|c|c|c|c|c|}
\hline \multirow[t]{2}{*}{ Groups } & \multicolumn{3}{|c|}{ Subgroups } & \multirow[t]{2}{*}{ Total } \\
\hline & Saline & EDTA & Laser+EDTA & \\
\hline $\begin{array}{c}\text { GP (control) } \\
\text { (Gutta-percha without sealer) }\end{array}$ & $\begin{array}{l}\text { GP saline } \\
\quad \mathrm{N}=8\end{array}$ & $\begin{array}{l}\text { GP EDTA } \\
\qquad \mathrm{N}=8\end{array}$ & $\begin{array}{c}\text { GP laser+EDTA } \\
\mathrm{N}=8\end{array}$ & 24 \\
\hline $\begin{array}{c}\text { AD } \\
(\mathrm{AD} \text { sealer })\end{array}$ & $\begin{array}{l}\text { AD saline } \\
\qquad \mathrm{N}=8\end{array}$ & $\begin{array}{l}\text { AD EDTA } \\
\qquad \mathrm{N}=8\end{array}$ & $\begin{array}{c}\text { ADlaser+EDTA } \\
\mathrm{N}=8\end{array}$ & 24 \\
\hline $\begin{array}{c}\text { BC } \\
\text { (Bioceramic sealer) }\end{array}$ & $\begin{array}{l}\text { BC saline } \\
\quad \mathrm{N}=8\end{array}$ & $\begin{array}{c}\text { BC EDTA } \\
\quad \mathrm{N}=8\end{array}$ & $\begin{array}{c}\text { BC laser+EDTA } \\
\mathrm{N}=8\end{array}$ & 24 \\
\hline \multicolumn{4}{|c|}{ Total } & 72 \\
\hline
\end{tabular}




\section{Scanning electron microscope:}

Nine additional teeth, one tooth designed for each group, prepared for SEM analysis to perceive the changes on root canal surfaces after the post space irrigations. All specimens were channeled buccolingually using diamond disk and separated longitudinally with chisel and mallet. One half of each root was randomly chosen for the scanning. With a lancet signifying the coronal, middle and apical thirds. Samples were fixed onto SEM. Superficial image was scanned using Quanta FEG 250 scanning electron microscope (FEI Company, USA). SEM settings were: $10.1 \mathrm{~mm}$ working distance, in-lens detector, excitation voltage of $10 \mathrm{KV}$ and 3000x magnification for root dentin interface.

Fiber post cementation: Glass Fiber Posts (GLASSIX plus, Nordin, Switzerland) were nominated. All posts were cleaned first using 70\% alcohol followed by $37 \%$ phosphoric acid etching for $15 \mathrm{sec}$ and then silanized with silane coupling agent (DentoBond Porcelain Fix, Itena, France) for 60 seconds then dried with an oil free air. RelyX U200 ( 3M ESPE, Seefeld, Germany) was injected into the root from the apical end to the entire length of the root canal. The posts were fixed in place with stable finger pressure for 10 seconds; microbrush was used for excess removal then light curing using light-polymerizing unit (Astralis 3, Ivoclar Vivadent, Liechtenstein) with $1150-\mathrm{mW} / \mathrm{cm}^{2}$ output for 20 seconds in all directions. Flowable composite (Charm core, Dentkist, Korea) was used for sealing the access. Samples were preserved in saline for one week till push out test.

Push out test: Each root was horizontally sectioned into 6 slices of $1.0 \pm 0.1 \mathrm{~mm}$ in thickness (each 2 slices indicated one third of the root: cervical, middle, and apical) leave-taking the last $4 \mathrm{~mm}$ from the apex using cutting machine. Marks were put on the coronal side of each slice for recognition of the coronal side during the pushout test. Push out test was completed using computer controlled materials testing machine (Instron universal testing machine, model 3345, England ) data calculated and documented using computer software (bluehill instron, England). The specimens were loaded with a $1 \mathrm{~mm}$ diameter cylindrical tip in an apical-coronal direction to push-out the post toward the broader part of the root slice to avoid the taper restriction. The cylindrical tip was put to touch only the post, Figure 1. The loads at failure were documented as $\mathrm{N}$ and the bond strengths were stated in $\mathrm{MPa} ; \mathrm{N}$ was divided by the area of the bonded interface, which

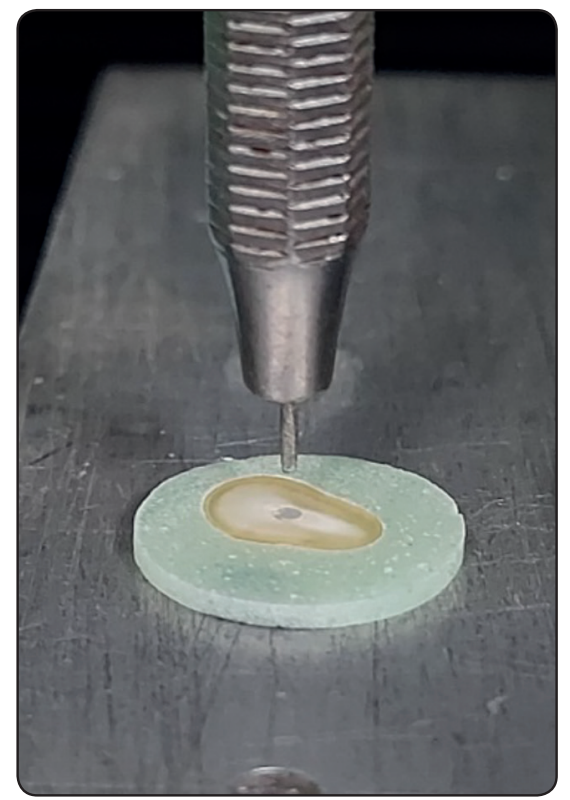

Fig. (1): Specimen positioned in the universal testing machine.

was calculated using the following formula:

Push out bond strength $=\mathrm{F} / \mathrm{A}$ where: $\mathrm{A}=\pi \mathrm{H}$ $(\mathrm{r} 1+\mathrm{r} 2)$

As $\pi$ is the constant $3.14, \mathrm{H}=1.5 \mathrm{~mm}$ is the thickness of the slice, $\mathrm{r} 1$ is the coronal radius of the slice and $\mathrm{r} 2$ is the apical radius.

\section{Fractographic analysis}

After push out test, the slices were observed under the Digital microscope (U500x Digital microscope, Guangdong, China). Each sample was snapped using USB Digital microscope with a built 
in camera connected with a compatible personal computer using a fixed magnification of $(65 \mathrm{X})$ to verify the failure mode, which was divided as follows; adhesive failure between resin cement and post and/or between adhesive resin cement and dentin, mixed failure with resin cement covering less than $50 \%$ of the post space, mixed with resin cement covering more than $50 \%$ of the post space, cohesive failure in dentin ( fracture in dentin), cohesive in post (fracture in post). Illustrative pictures of the failure pattern are shown in Figure 7. ${ }^{(18)}$

\section{RESULTS}

The results were analyzed using Graph Pad Instat (Graph Pad, Inc.,USA) software for windows. A value of $\mathrm{P} \leq 0.05$ was measured statistically significant. After homogeneity of variance and normal distribution of errors had been confirmed, analysis of variance ANOVA was completed for comparison between main groups followed by Tukey's pairwise if presented significant results. Also, three-way ANOVA was done to identify total effect of each variable (main groups, dentin treatment and region). Chi square test was done between failure mode patterns. Sample size ( $n=24 /$ group) was large enough to discover large effect sizes for main effects and pair-wise comparisons, with the satisfactory level of power set at $80 \%$ and a 95\% confidence level.

\section{Push out bond strength (MPa) test results}

The mean values and standard deviation of push out bond strength test results measured by mega Pascal (MPa) for all groups as function of dentin pretreatment applied and radicular region are summarized in Table (2) and graphically drawn in Figure (2).

In GP group; it was found that dentin pretreatment with (Laser+EDTA) recorded the highest mean $\pm \mathrm{SD}$ value followed by EDTA meanwhile, saline treated dentin was recorded the least mean \pm SD value. The difference between dentin pretreatment was statistically non-significant as designated by two-way ANOVA ( $p>0.05)$. There was no significant $(\mathrm{P}>0.05)$ difference between radicular regions, whereas; middle third recorded the highest bond strength followed by cervical, while the apical third recorded the lease value.

In AD seal group; (Laser+EDTA) treated dentin recorded the highest mean $\pm \mathrm{SD}$ value followed by EDTA, whereas; the saline treated dentin was recorded the least mean \pm SD values. The difference between dentin pretreatment was statistically significant as designated by two-way ANOVA $(\mathrm{P}<0.05)$. There was no significant $(\mathrm{P}>0.05)$ difference between radicular regions where cervical third recorded the highest bond strength followed by the middle, while the apical third recorded the least value.

In BC group; (Laser+EDTA) treated dentin recorded the highest mean \pm SD value followed by EDTA, while the saline treated dentin was recorded the least mean \pm SD values. The difference between dentin pretreatment was statistically significant as designated by two-way ANOVA $(\mathrm{P}<0.05)$. Also, the difference between radicular regions was significant $(\mathrm{P}<0.05)$, where cervical third recorded the highest bond strength followed by middle, while the apical third recorded the least value.

\section{Interactions of variables}

Regarding the main sealer groups without taking into consideration dentin pretreatment or radicular region, sealer type influenced push-out bond strength mean values significantly as proven by three-way ANOVA $(\mathrm{P}<0.05)$, where ADseal group recorded the highest push-out bond strength results followed by the GP group while BC group recorded the least values .

Regarding the dentin pretreatment without taking into consideration sealer group or radicular region, dentin pretreatment affected push- 
TABLE (2) Push out bond strength (MPa) results (Mean values \pm SDs) for all groups as function of dentin pretreatment and radicular region.

\begin{tabular}{|c|c|c|c|c|c|c|c|c|c|}
\hline \multirow{3}{*}{ Variable } & \multicolumn{9}{|c|}{ Dentin pretreatment } \\
\hline & \multicolumn{3}{|c|}{ Saline } & \multicolumn{3}{|c|}{ EDTA } & \multicolumn{3}{|c|}{ EDTA +Laser } \\
\hline & Cervical & Middle & Apical & Cervical & Middle & Apical & Cervical & Middle & Apical \\
\hline GP group & $3.5 \pm 0.5$ & $4.52 \pm 1.2$ & $3.43 \pm 1.41$ & $3.61 \pm 0.8$ & $4.49 \pm 1.6$ & $5.01 \pm 1.2$ & $4.46 \pm 1.1$ & $4.50 \pm 0.9$ & $4.39 \pm 0.9$ \\
\hline$A D$ group & $4.1 \pm 0.9$ & $4.2 \pm 0.8$ & $3.59 \pm 0.6$ & $6.18 \pm 1.1$ & $6.01 \pm 1$ & $5.17 \pm 0.8$ & $8.1 \pm 1.1$ & $6.9 \pm 1.09$ & $7.6 \pm 1.4$ \\
\hline BC group & $2.6 \pm 0.6$ & $2.2 \pm 0.6$ & $1.8 \pm 0.3$ & $3.41 \pm 0.89$ & $2.7 \pm 0.74$ & $2.9 \pm 0.8$ & $4.2 \pm 0.72$ & $3.7 \pm 0.8$ & $3.45 \pm 1.2$ \\
\hline \multirow{5}{*}{ Statistics } & \multicolumn{2}{|c|}{$\begin{array}{c}p \text { value } \\
\text { (between sealer group) }\end{array}$} & $0.007 *$ & \multicolumn{2}{|c|}{$\begin{array}{c}p \text { value } \\
\text { (between sealer group) }\end{array}$} & $0.019 *$ & \multicolumn{2}{|c|}{$\begin{array}{c}p \text { value } \\
\text { (between sealer group) }\end{array}$} & $0.0004^{*}$ \\
\hline & \multicolumn{2}{|c|}{$\begin{array}{c}p \text { value } \\
\text { (between region) }\end{array}$} & $0.163 n s$ & \multicolumn{2}{|c|}{$\begin{array}{c}p \text { value } \\
\text { (between region) }\end{array}$} & $0.996 n s$ & \multicolumn{2}{|c|}{$\begin{array}{c}p \text { value } \\
\text { (between region) }\end{array}$} & $0.234 n s$ \\
\hline & \multirow{3}{*}{\multicolumn{2}{|c|}{$\begin{array}{c}\text { p value between dentin } \\
\text { pretreatment }\end{array}$}} & GP group & \multicolumn{6}{|c|}{$0.3652 n s$} \\
\hline & & & $A D$ group & \multicolumn{6}{|c|}{$0.0013 *$} \\
\hline & & & BC group & \multicolumn{6}{|c|}{$0.0008 *$} \\
\hline
\end{tabular}

*; significant $(p<0.05) \quad$ ns; non-significant $(p>0.05)$

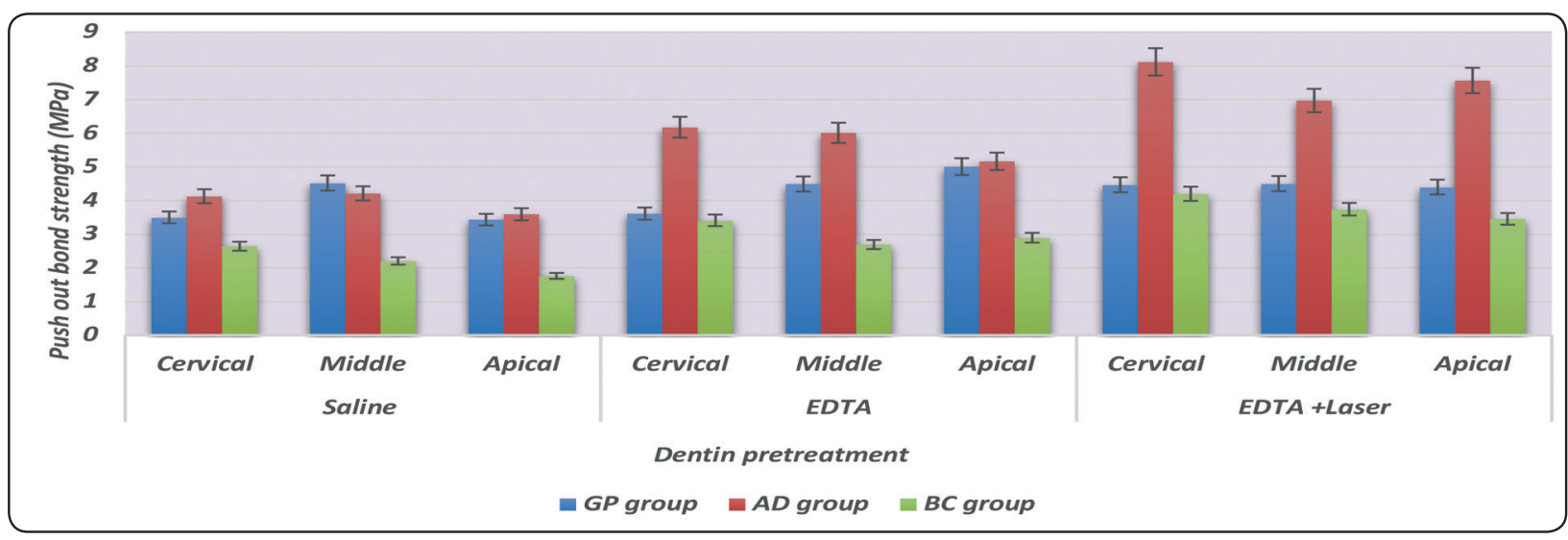

Fig. (2): Histogram of the mean values of push out bond strength test results measured by mega Pascal (MPa) for all groups as function of dentin pretreatment applied and radicular region.

out bond strength mean values significantly as demonstrated by three-way ANOVA $(\mathrm{P}<0.05)$, where (Laser+EDTA) recorded the highest pushout bond strength followed by EDTA while saline recorded the least values.

Regarding the three radicular regions, without taking into consideration the sealer or dentin treatment, there was a statistically non-significant difference in push-out bond strength mean values among the radicular regions for all group as indicated by three-way ANOVA $(\mathrm{P}<0.05)$, where the coronal region showed the highest push-out bond strength results followed by the middle third while the apical regions, recorded the least value.

\section{Results of Fractographic analysis}

Failure patterns are presented in Table 3.

In GP group, it was found that samples revealed predominantly adhesive failure mode between tooth and resin $(40.28 \%$ ), while mixed failure $(<50 \%$ and $>50 \%)$ were recorded $(31.94 \%$ and $6.94 \%$ respectively), however, cohesive failure in 
(20.83\%) only with no record for adhesive failure mode between post and resin $(0 \%)$.

In $\boldsymbol{A D}$ group, it was found that majority of samples revealed predominantly mixed failure mode $(<50 \%$ and $>50 \%)$ were $(23.61 \%$ and $20.83 \%$ respectively), followed by adhesive failure between tooth and resin (38.89\%), whereas, cohesive failure was $(12.5 \%)$ only with minor record for adhesive failure between post and resin (4.17\%). In BC group, it was found that samples displayed predominantly, mixed failure mode $(<50 \%$ and $>50 \%$ ) were (27.78\% and $26.39 \%$ respectively), followed by adhesive failure between tooth and resin (38.89\%), whereas, cohesive failure was in $(6.94 \%)$ only with no record for adhesive failure between post and resin $(0 \%)$. The difference in failure mode patterns between groups was statistically significant as TABLE (3): Frequent distribution of failure mode patterns (\%) for all groups as function of dentin pretreatment applied and radicular region.

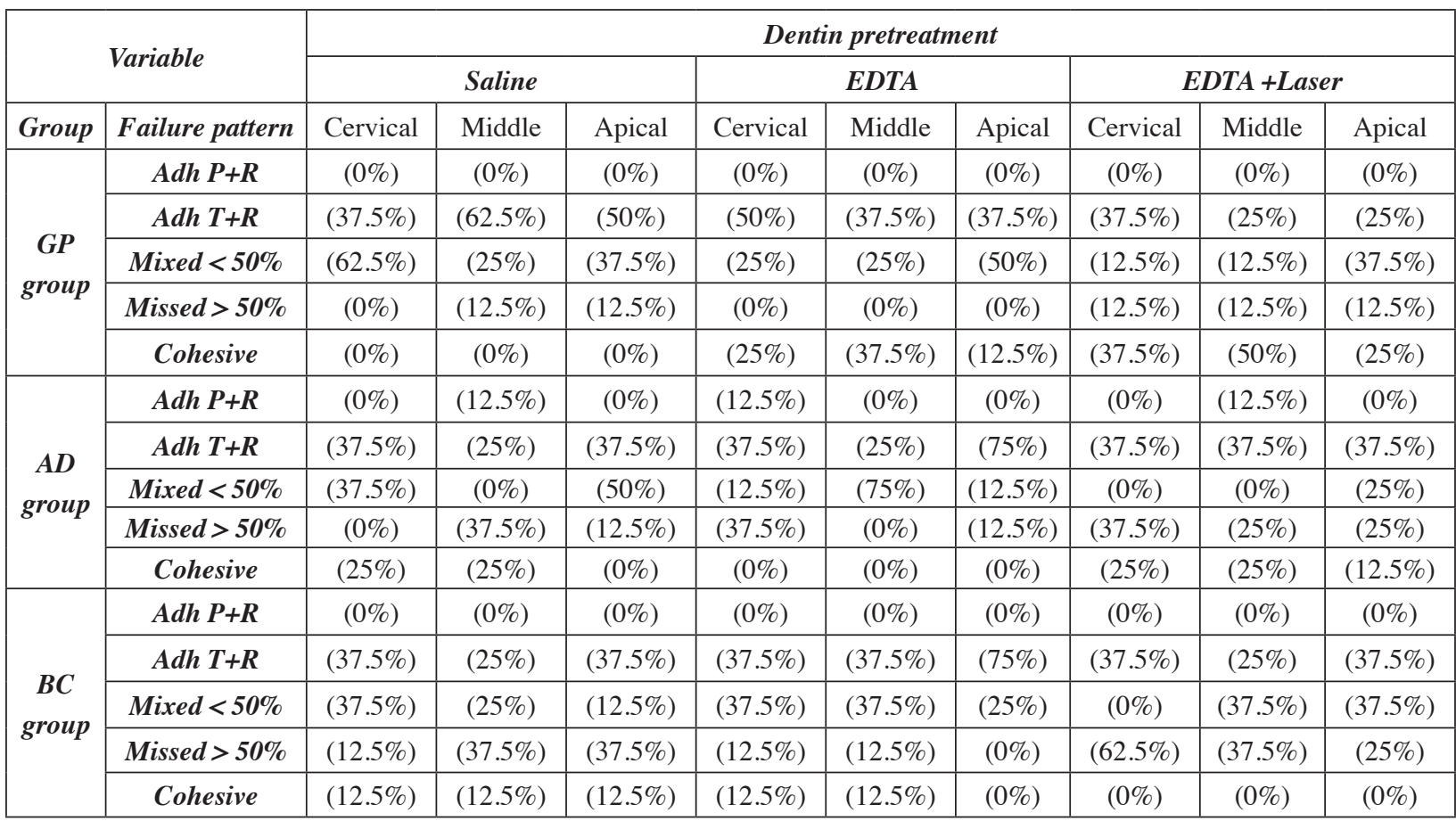

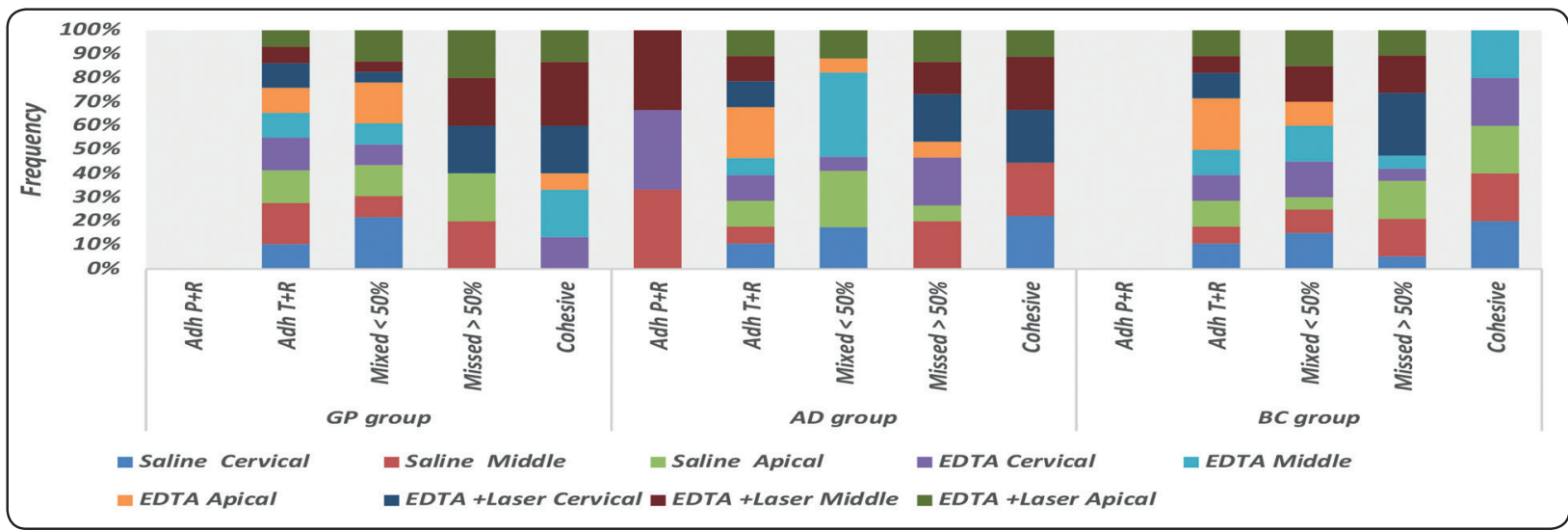

Fig. (3): Stacked column chart of frequent distribution of failure mode patterns (\%) for all groups as function of dentin pretreatment applied and radicular region. 


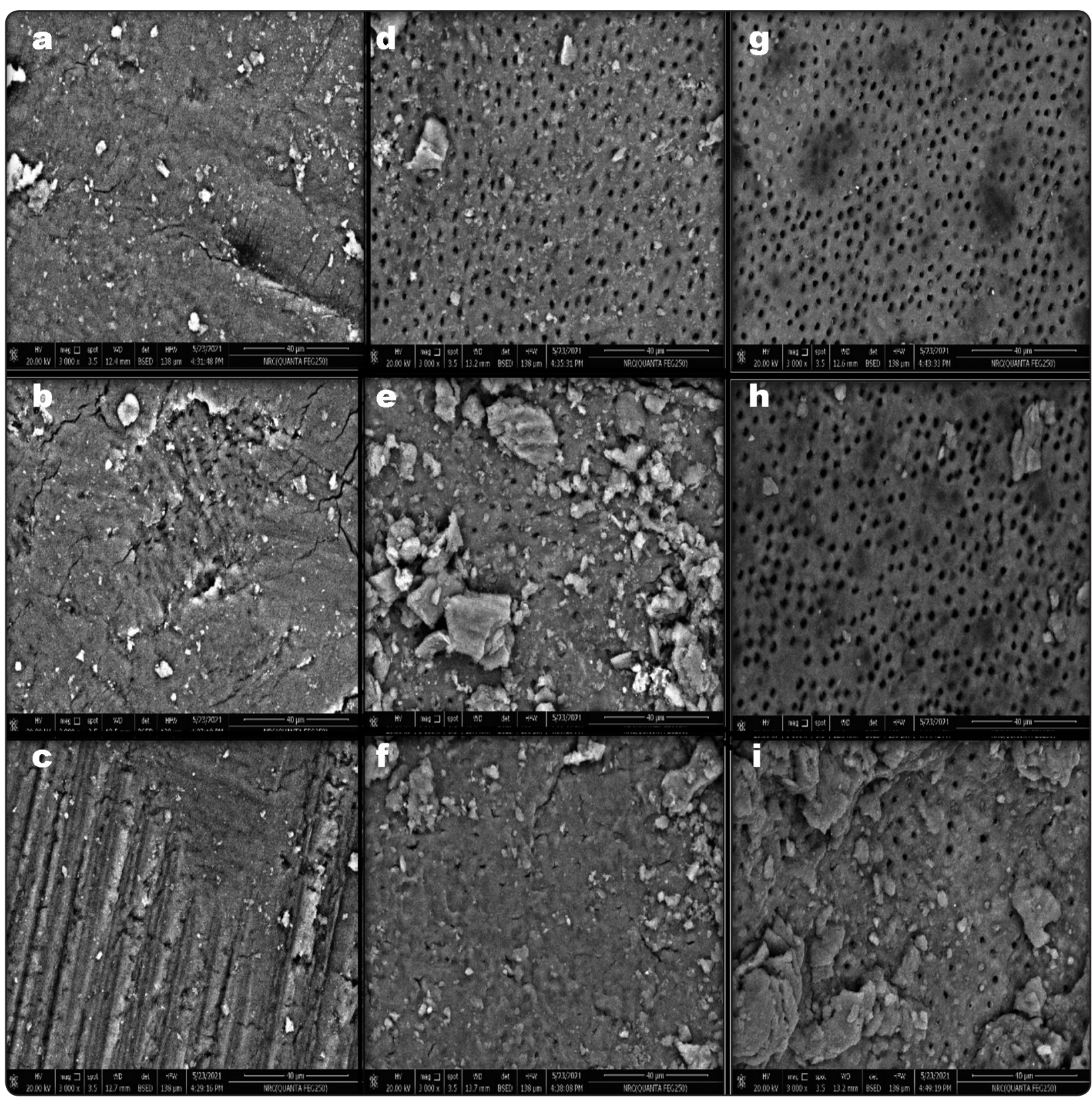

Fig. (4): SEM images representative the post spaces in GP group at X3000, treated with: 1. Saline (a: coronal third; b: middle third; c: apical third), 2. EDTA (d: coronal third; e: middle third; f: apical third), and 3. (Laser +EDTA) (g: coronal third; h:middle third; i:apical third). a, b and c: The smear layer covering root canal dentin surface in forms of crystals with irregular forms and shapes. d: Absence of smear layer and slight presence of remnants, opened dentinal tubules. e: Frequent presence of remnants; smear layer covering the dentin surface, and the dentinal plugs remained . f: Frequent presence of remnants; thick smear layer covering root canal dentin surface in forms of crystals with irregular forms and shapes. g: Clean dentinal surface opened dentinal tubules absence of remnants. h: clean dentin surface, opened dentinal tubules, slight presence of remnants. i: Frequent presence of remnants; smear layer covering the dentin surface, and the dentinal plugs remained. 


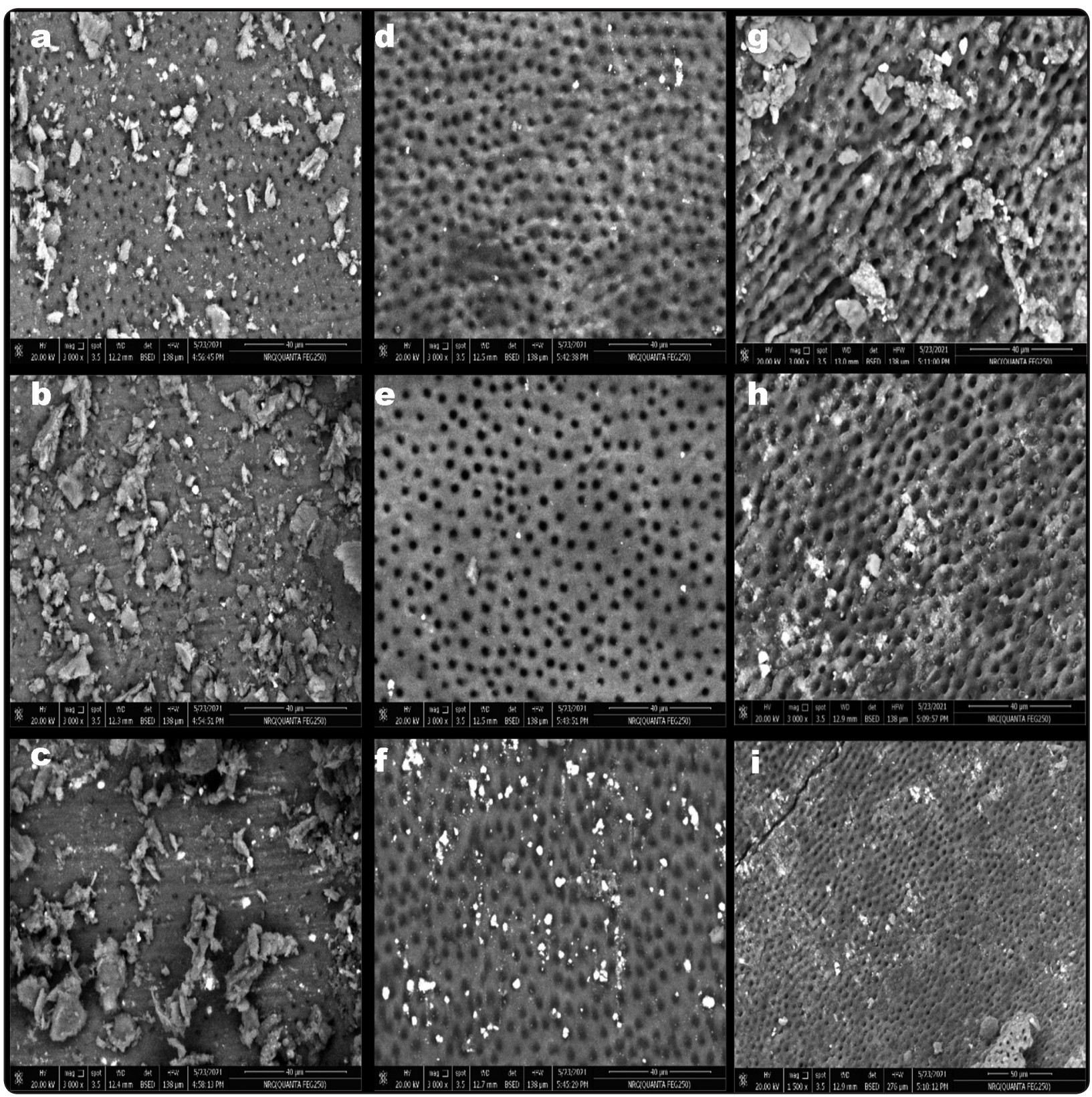

Fig. (5): SEM images representative the post spaces in AD group at X3000, treated with: 1. Saline (a: coronal third; b:middle third; c:apical third), 2. EDTA (d: coronal third; e:middle third; f:apical third), and 3. (laser +EDTA) (g: coronal third; h:middle third; i:apical third). a: Slight presence of remnants, less smear layer covering the dentin surface. b and c: Frequent presence of remnants, thick smear layer no dentinal tubules are visible. d and e: Absence of smear layer and open dentinal tubules. f: Slight presence of remnants, absence of smear layer and open dentinal tubules. $\mathbf{g}, \mathbf{h}$ and $\mathbf{i}$ : Slight presence of remnants absence of smear layer and opened dentinal tubules. 


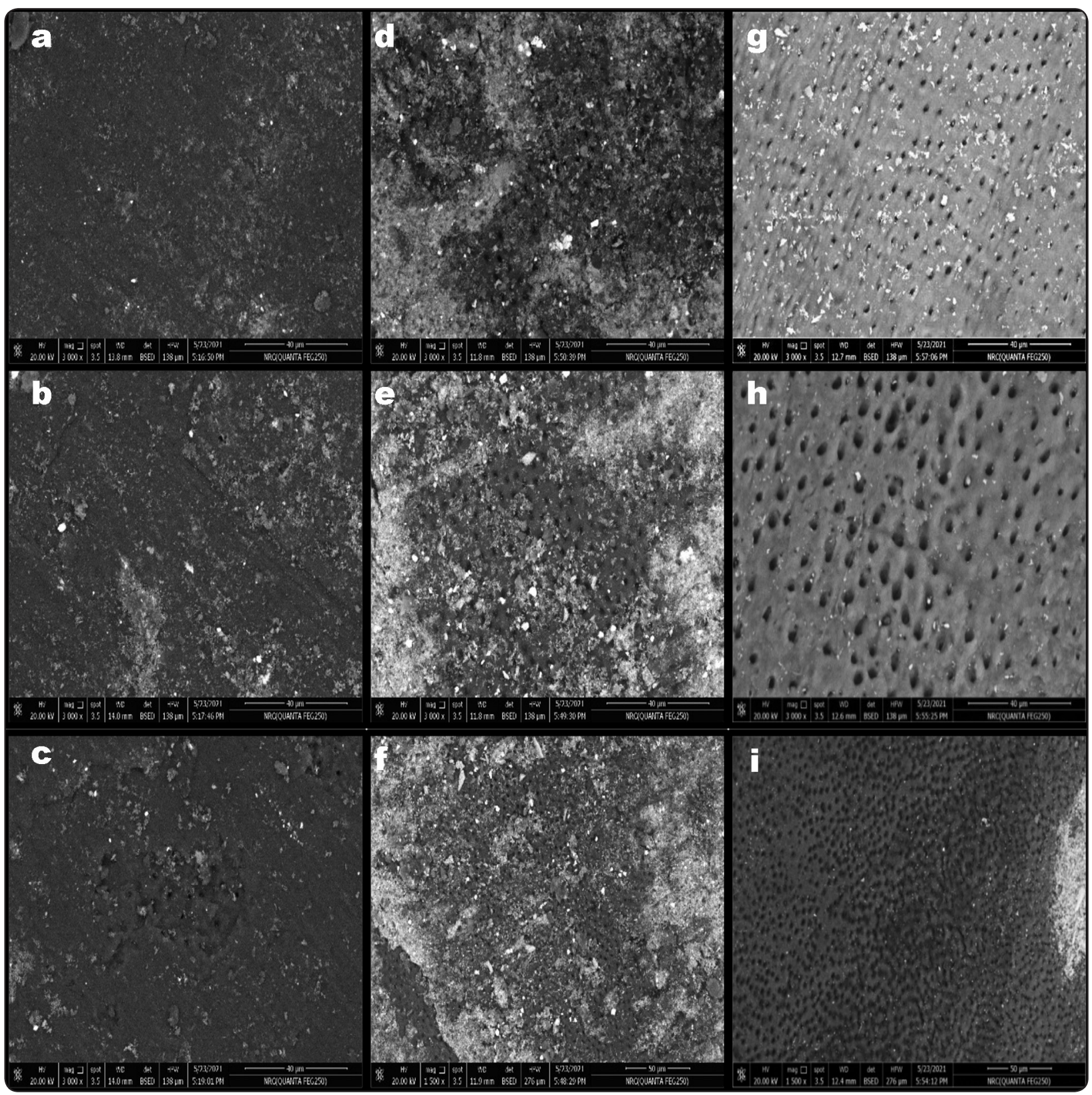

Fig. (6): SEM images representative the post spaces in BC group at X3000, treated with: 1.Saline (a: coronal third; b:middle third; c:apical third), 2.EDTA (d: coronal third; e:middle third; f:apical third), and 3.(laser +EDTA) (g: coronal third; h:middle third; i:apical third). a, b and c: Thick smear layer covering root dentin surface. d, e and $\mathbf{f}$ : Showing some removal of smear layer, some of dentinal tubules are partially opened and dentinal plugs remained. $\mathbf{g}, \mathbf{h}$ and $\mathbf{i}$ : Absence of smear layer and open dentinal tubules. 
proved by Chi square test $(\mathrm{P}<0.05)$. Analysis of the failure modes in the present study revealed no cohesive failures within the post for all groups.

\section{Interpretation of the Scanning Electron micro- scope (SEM) examination}

Dentin surface of the root canal were examined by SEM after different surface treatments with; Saline, EDTA, and (Laser+ EDTA), Figure (4, 5, and 6).
In GP group; SEM revealed dense deposits of smear layer on the dentine surface of the root canal, and smear lump was found occluding the dentinal tubules after saline flushing the canal. As well as after EDTA treatment there was frequent remnants; smear layer still covering the dentin surface, and the dentinal plugs persisted. While after (Laser and EDTA) treatment, clean dentinal surface was noticed, opened dentinal tubules and absence of remnants above root dentin. In AD group; SEM presented

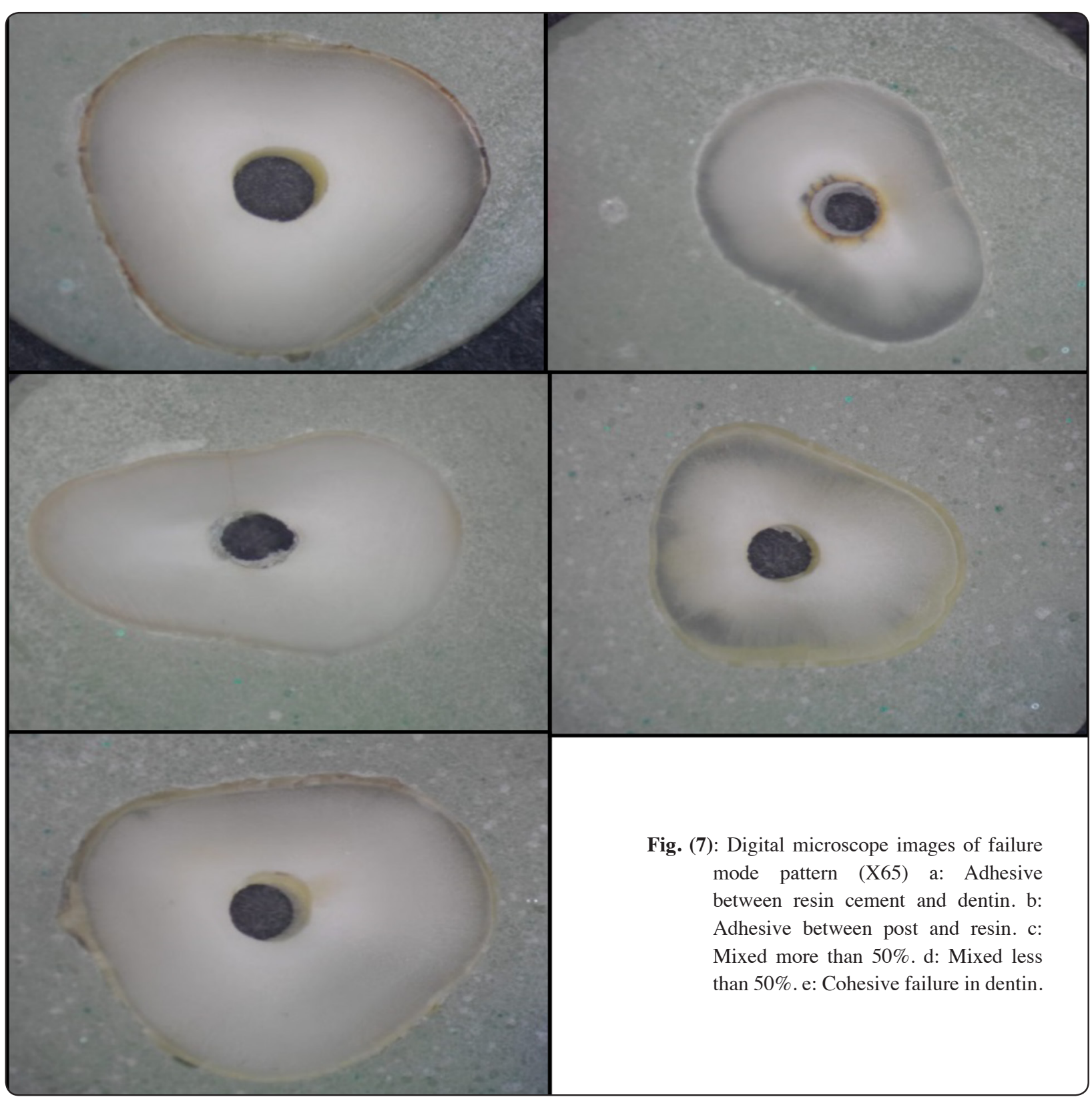


frequent remnants and thick smear layer with no visible dentinal tubules after saline pretreatment; while after EDTA, and (laser and EDTA) treatment, there was absence of smear layer and there was opened dentinal tubules. In BC group; SEM presented a thick smear layer covering root dentin surface after saline flushing. Whereas, after EDTA treatment there was some removal of smear layer but the dentinal plugs remained. However there was opened dentinal tubules and absence of smear layer after (laser and EDTA) treatment.

\section{DISCUSSION}

The present study evaluated the effect of laser activated irrigation on bond strength of fiber post to radicular dentin after endodontic retreatment using two types of sealers. The results showed that, laser irradiation with EDTA irrigation improved significantly the push-out bond strength of fiber post to radicular dentin after endodontic retreatment using bioceramic or epoxy-based sealer. Additionally, epoxy based sealer recorded higher push out bond strength of fiber post than bioceramic sealer after all supplementary dentin pretreatment. So the first and second null hypotheses were rejected.

Bioceramic sealer was selected in the present study because it is a novel category of high-purity tricalcium silicate sealer, having specific setting feature as it consumes the inherent moisture in dentinal tubules ${ }^{(7)}$. Their exclusive setting activity and hardness could improve their adhesion and resistance to dislocation from dentin especially during the secondary endodontic therapy. ${ }^{(8)}$ The argument on the removal of the bioceramic sealers during retreatment is a matter of concern among clinicians. Consequently, attempts must be made to eradicate sealer deposits from the post space to boost the bond strength of fiber post and resin cement to dentinal walls. ${ }^{(14)}$

Laser parameters applied in this study were (980nm diode laser, $2.5 \mathrm{~W} /$ pulse and $20 \mathrm{~Hz}$ frequency for 20 second). These parameters were selected simulating clinical conditions ${ }^{(16)}$, which settled with Gogarkhay et al. ${ }^{(19)}$ who described that diode laser was a safe tool for routine clinical use. Previous researches ${ }^{(16,19)}$ have emphasized that the flexible light-conductor fiber, should be kept in constant motion in the root canal during irradiation to avoid rise in temperature on the root surface. For this reason, constant motions were used in this study. Some authors suggested that the radiation of diode lasers is poorly absorbed by hard dental tissues and accordingly permits propagation, scattering, or diffused transmission of light through dentin. Laser activated irradiation (LAI) has been claimed to augment smear layer and dentine debris eradication from root canal walls. (20) However, there is still no sufficient data on the sealer removal after retreatment using laser irradiation.

Posts dimensions were standardized for investigational control to allow comparison between groups without bias at the current study.

One of the most important factors affecting the bond strength of the fiber post to root dentin is the adhesive cement used; in this study self-adhesive resin cements have been used to eradicate possible errors of intra-radicular bonding, simplifying cementation procedure. ${ }^{(21)}$

The effect of each sealer on the bond strength of fiber posts was evaluated by a thin-slice push-out test, which requires 1-mm-thick root disks. Plunger size diameter was selected according to root canal diameter. This method results in more reliable, reproducible and clinic-like conditions than other tests. ${ }^{(22)}$

The selection of $17 \%$ EDTA Irrigating solutions were based on previous studies ${ }^{(10,20)}$ of endodontic protocols used to remove the smear layer before filling.

With all dentin pretreatment protocols, the results of the current study demonstrated that the AD seal group recorded the highest bond strength mean values of fiber posts, followed by control group, while BC sealer group recorded the 
least values; the difference between groups was statistically significant as indicated by two-way ANOVA $(\mathrm{P}<0.05)$. These findings agreed with the results reported by several studies shown by Chen et al. ${ }^{(21)}$ and Oltra et al. ${ }^{(23)}$. Chen et al ${ }^{(21)}$ investigated the effect of ultrasound and regular rinsing on smear layer removal after post space preparation using different sealers (AH Plus, Apexit Plus and iRoot SP ), the results showed that AH Plus presented the easiest removal from the post space, whereas iRoot SP presented the most difficult removal. Oltra et al (23) examined the retreatability of BioCeramic sealer as compared with AH Plus with Chloroform solvent. The results revealed that the BC sealer group had significantly more residual filling material than the AH Plus group regardless of whether or not both sealers were retreated with chloroform. This notable difference between the sealers might be attributed to the fact that $\mathrm{BC}$ nanoparticle leads to deeper penetration of the sealer into the dentinal tubules. ${ }^{(24,25)}$ Additionally, presence of the moisture inside the dentinal tubules activated the reaction between calcium phosphates and calcium hydoxide incorporated in the sealer, producing hydroxyl appetite. (26) This hydroxyl appetites precipitated with the calcium silicate hydrate phase to produce a composite like structure reinforcing the set cement that decreased root dentin adhesion to resin cement and fiber post ${ }^{(14,27)}$.

The results of the present study showed high bond strength in the AD sealer irrigated with saline (control), these findings agreed with the results reported by several studies, ${ }^{(21,23)}$ the most probable explanation might be the fact that the epoxy-based sealer has no reversing effect on the adhesion of resin cement. This result supported by Cohen et al. ${ }^{(28)}$ who reported that epoxy resin, such as AD seal, does not interfere with the activation of free radicals in composite resin. Cecchin et al. ${ }^{(29)}$ reported that the high bond strength of resin-based sealers is due to the presence of epoxy resin in their composition, which is similar to the composition of the resin cement.
On the other hand, the results of the current study demonstrated that the bond strength improved significantly after EDTA and (laser and EDTA) treatment in both sealers. These results come in accordance with Elnaghy ${ }^{(30)}$ who found that, the self-adhesively cemented fiber posts after irrigation of the root dentin with EDTA recorded greater bond strength than rinsing with distilled water. Elnaghy also confirmed significantly less smear layer and opened dentinal tubules after EDTA irrigation compared to other irrigants. EDTA solution has great special effects on demineralization of the inorganic dentin components, which effects periand intertubular dentin and smear layer removal. (31) During irrigation, EDTA captures the calcium ions $(\mathrm{Ca}+2)$, each EDTA molecule can bind with a single calcium ion, until balance occurred, then no more dissolution. ${ }^{(10,20)}$ Consequently, increasing dentin penetrability and empowers direct contact of the resin cement with the dentinal walls. ${ }^{(31)}$ Moreover, EDTA has the ability to dissolve epoxy based sealers as reported by Kelea and Koseaglo ${ }^{(32)}$; who measured the solubility of six sealers (calcium hydroxide, polyketone, zinc oxide-eugenol, silicone and two epoxy resins) in EDTA and $\mathrm{NaOCl}$. Authors demonstrated that EDTA and $\mathrm{NaOCl}$ allowed solubility of both tested epoxy resin sealers in the nonsurgical endodontic retreatment. This could be explaining the higher bond strength resulted from dentin pretreatment of the post space with EDTA in ADseal group than BC sealer group. As depicted from SEM (Figure 5 and 6), SEM examination of radicular dentin in $\mathrm{AD}$ sealer group treated with $17 \%$ EDTA revealed, complete removal of the smear layer and opening the dentinal tubules, while in BC sealer EDTA group; resulted in partial removal of smear layer, some of dentinal tubules are partially opened and the dentinal plugs remained. This is supported by previous study by Garrib and Camiller (33) who investigated the effect of $17 \%$ EDTA, for 5 min on Total fill Bioceramic sealer. They found that $17 \%$ EDTA affected the structural integrity only of the sealer. 
The results of the current study verified that dentin pretreatment of the post space by (Laser irradiation + EDTA) significantly Improved the bond strength of fiber post than EDTA irrigation only in all tested groups verifying the positive effect of the diode laser. This was associated with the removal of smear layer, remaining gutta-percha and endodontic sealers from the radicular dentin ${ }^{(20,34)}$ as shown in SEM (Figure 4, 5 and 6). The results coincide with previous study ${ }^{(35)}$ who reported the improved bond strength of fiber posts cemented to the intraradicular dentine surface previously irradiated with highintensity diode laser emitting at $980 \mathrm{~nm}$. Strefezza et al (36) analyzed the effect of dentin root canal irradiation - with high intensity diode laser, at 830 $\mathrm{nm}$, operating in continuous or pulsed mode- on the retention of metal or fiber posts, cemented with self-etching resin composite (Panavia F) and zinc phosphate cement (ZnPO4). Authors detected that the higher bond strength values between cement and radicular dentin for the irradiated groups, associated with removal of smear layer and remaining guttapercha from the radicular dentine. This result might be attributed to activation of chemical irrigants by heating, as they are more efficient at higher temperature, which increases the rate at which it softens and dissolves gutta-percha. ${ }^{(37)}$ Additionally the laser melts and vaporizes the smear layer from radicular dentine, resulting in clean root canal walls. The thermal effect of the radiation penetrates up to $1 \mathrm{~mm}$ into the dentinal walls, permitting a decontaminating effect on deeper dentine layers. (38) Previous studies ${ }^{(39,40)}$ have described the laser actions in removal the root canal filling materials which includes a combination of both photothermal and photoablation effects. The photothermal effect depends on conversion of the photon energy of laser to thermal energy. The thermal energy then produces heat, which subsequently melts filling material in the root canal, while the photoablation mechanism was achieved by the water between the laser light and the irradiated surface, which then produced the ablation of the gutta-percha material and sealer. ${ }^{(41)}$
In GP group, the results presented that the dentin pretreatment with EDTA was not significantly improved the bond strength. This could be attributed to endodontic retreatment step involves the action of using drills to remove the gutta percha which resulted in a plasticizing layer of gutta percha and inorganic components forming a new adherent smear layer on the canal wall, which can occlude the dentinal tubules. ${ }^{(4)}$ Additionally, the chloroform used during endodontic retreatment probably resulted in a thin layer of gutta-percha deposited on canal walls that saturated the root dentin interfering with resin cement bonding. This finding was supported by previous study ${ }^{(42)}$. Consequently, cleaning the canal with EDTA only didn't remove the gutta percha remnants from the dentin walls thus, affecting the bond strength negatively, expressed by low bond strength of fiber post in this sub-group. As well as SEM analysis verified our results (Figure 4; e and f) displayed a heavy depositions and thick smear layer in middle and apical thirds after EDTA treatment.

Concerning the post push out bond strength at different root levels with all dentin pretreatment protocol; it was observed that the coronal region showed the highest mean push-out bond strength, followed by the middle while the apical region recorded the least values with non-significant differences $(\mathrm{P}>0.05)$ between them. This result came in agreement with other studies ${ }^{(43,44)}$ reported nonsignificant effect of root canal region bond strength to dentin in cases of fiber root reinforcement. Authors explained this result as the dependence of bond strength on the surface area of intertubular dentin than to tubule density. ${ }^{(45,46)}$ On the other hand, our results contradict previous studies ${ }^{(47,48)}$ that detected increased bond strength significantly in coronal and middle regions than apical one. Authors attributed this to morphological differences, such as the reduction in the number, density, and diameter of dentinal tubules. Another explanation for low bond strength in the apical third is the difficulty of complete filling material removal at such deepest thirds. Therefore, the dentinal tubules of the apical 
area, covered by a filling material, which act as a mechanical barrier, prevent adhesion, with the intraradicular dentin in this region.

Regarding the types of failures found in the present study, AD sealer group had significantly higher incidence of mixed followed by adhesive with minimal cohesive failures. This result was probably due to significantly higher bond strength values. BC sealer group demonstrated predominantly mixed failure mode between tooth and resin followed by adhesive failure mode, while cohesive failure mode was minor. This result might be attributed to the positive effect of complementary dentin pretreatment in cleaning the canal walls resulting in increased bond strength of adhesive resin cement with the radicular dentin. While GP group demonstrated predominantly adhesive failure mode between tooth and resin followed by mixed failure mode, with minimal presence of cohesive failure existing in EDTA and (Laser with EDTA) dentin pretreatment groups. This result was probably due to the weak bond strength of fiber post due to presence of thick smear layer in (saline) and (EDTA) pretreated groups that started to be removed by (laser +EDTA) treated group. ${ }^{(43,46)}$

However, this study has some limitations, first; the samples were not subjected to thermal and mechanical cyclic loading as these steps simulate oral masticatory function and teeth aging in clinical circumstances, second; additional clinical testing is advised.

\section{CONCLUSIONS}

Within the limitation of this study, the following conclusions were drawn:

1. Supplementary dentin pretreatment with laser and EDTA before post cementation revealed improvement in the bond strength of fiber post to radicular dentin for both epoxy-based sealer and Bioceramic sealer previously used in endodontic retreatments.
2. The type of endodontic sealer used in root canal filling affected the bond strength of fiber posts to root dentin.

3. The use of an epoxy resin-based sealer demonstrated better results than the use of Bioceramic sealer with all tested dentin pretreatments.

4. Radicular region had no effect on bond strength of fiber post.

\section{REFERENCES}

1. Qualtrough A. and Mannocci F. Tooth-colored post systems: a review. Oper Dent. 2003; 28(1):86-91.

2. Pereira KF, Vencão AC, Magro MG, Belizário LG, Porto TS, Andrade MF, Duarte MAH, Kuga MC. Effect of endodontic retreatment on the bond strength of resin cements to root canal dentin. Am J Dent. 2019 Jun; 32(3):147-151.

3. Pelegrine RA, Paulillo LMS, Kato AS, Fontana CE, Pinheiro SL, Martin AS and Bueno CE. Effect of endodontic retreatment on push-out bond strength and quality of fiber postbonding interface of resin cements. J Contemp. Dent Pract. 2016; 17 (1):42-48.

4. Serafino C, Gallina G, Cumbo E, Ferrari M. Surface debris of canal walls after post space preparation in enddontically treated teeth: A scanning electron microscopic study. Oral Surg oral Med Oral Pathol Oral Radiol Endod 2004; 97(3): 381-387.

5. Demiryurek EO, Kulunk S, Sarac D, Yuksel G, Bulucu B. Effect of different surface treatments on the push-outbond strength of fiber post to root canal dentin. Oral Surg. Oral Med Oral Pathol Oral Radiol Endod. 2009; 108: e74-80.

6. Bengoa PF et al. Effect of ultrasonic cleaning on the bond strength of fiber posts in oval canals filled with a premixed bioceramic root canal sealer: Res. Dent Endod. 2020, May;45(2):e19

7. Zhang H, Shen Y, Ruse ND, Haapasalo M. Antibacterial activity of endodontic sealers by modified direct contact test against Enterococcus faecalis. J Endod. 2009; 35(7):1051-5.

8. Kim H, Kim E, Lee SJ, Shin SJ. Comparisons of the retreatment efficacy of calcium silicate and epoxy resinbased sealers and residual sealer in dentinal tubules. J Endod. 2015; 41: 2025-2030. 
9. Meyappan R, Narayana SS, Kannan K, Ahmed AS, Deepa VK, Kulandaivelu A. Effectiveness of conventional and three different rotary retreatment techniques in canals obturated with gutta-percha: a scanning electron microscope study. J Endod 2014; 26:259-265.

10. Hmud R, Kahler WA, George R, Walsh LJ. Cavitational effects in aqueous endodontic irrigants generated by nearinfrared lasers. J Endod. 2010; 36:275-278.

11. Paiva SS, Siqueira JF, and Rocas IN. Molecular microbiological evaluation of passive ultrasonic activation as a supplementary disinfecting step: a clinical study. J Endod 2013; 39:190-4.

12. Cheng X, Guan S, and Lu H. Evaluation of the bactericidal effect of Nd:YAG, Er:YAG, Er,Cr:YSGG laser radiation, and antimicrobial photodynamic therapy (aPDT) in experimentally infected root canals. Lasers Surg Med. 2012; 44:824-31.

13. Costa R, Nogueira G, Antoniazzi J, Moritz A and Zezell D: Effects of Diode Laser $(810 \mathrm{~nm}$ ) Irradiation on Root Canal Walls: Thermographic and Morphological Studies. J. Endo. 2007; 33 (3): 252 - 255.

14. Kakoura F et al: Retreatment Efficacy of Endodontic Bioceramic Sealers: A Review of the Literature. Odovtos [online]. 2018, vol.20, n.2, pp.39-50.

15. Aleisa K, Alghabban R, Alwazzan K, Morgano SM. Effect of three endodontic sealers on the bond strength of prefabricated fiber posts luted with three resin cements. J Prosthet Dent. 2012; 107(5):322-6.

16. Marchesan MA, Junior AB, Gabriel AE, Silva SR. and Neto MD: Ultrastructural Analysis of Root Canal Dentine Irradiated with 980-nm Diode Laser Energy at Different Parameters. Photomed. Laser Surg. 2008; 26(3): 235-240.

17. Schoop U, Kluger W, and Dervisbegovic S. Innovative wavelengths in endodontic treatment. Lasers Surg Med. 2006; 38:624-30.

18. Mohammadi N, Oskoee SS, Kalmamoui MA, et al: Effect of Er, CR:YSGC pre treatment on bond strength of fiber post to root canal dentin using self adhesive resin cement .Lasers Med SCi 2013;28:65-69 .

19. Goharkhay K.,Mortiz A., Wilder-Smith P., Schoop U., Kluger W., Jakolitsch S. and Sperr W.: Effects on oral soft tissue produced by a diode laser in vitro. Laser Surg. Med. 25: 401-406; 1999.

20. Lloyd A, Uhles JP, Clement DJ, et al: Elimination of intracanal tissue and debris through a novel laser-activated system assessed using high-resolution micro-computed tomography: a pilot study. J Endod. 2014;40: 584-587.

21. Chen X et al: Effects of Endodontic Sealers and Irrigation Systems on Smear Layer Removal after Post Space Preparation. JOE;2018;44 (8):1293-1297

22. Goracci C, Grandini S, Bossù M, Bertelli E, Ferrari M. Laboratory assessment of the retentive potential of adhesive posts: a review. J Dent. 2007; 35: 827-35.

23. OLtra E et al: Retreatability of two endodontic sealers, EndoSequence BC Sealer and AH Plus: a microcomputed tomographic comparison. Restor Dent Endod. 2017; 42(1):19-26)

24. Hess D, Solomon E, Spears R, He J. Retreatability of a bioceramic root canal sealing material. J Endod. 2011; 37(11):1547-9.

25. Ersev H, Yılmaz B, Dincol M, Dağlaroğlu R. The efficacy of ProTaper Universal rotary retreatment instrumentation to remove single gutta-percha cones cemented with several endodontic sealers. Int Endod J. 2012; 45(8):756-62.

26. Candeiro GT, Correia FC, Duarte MA, et al: Basic research: evaluation of radiopacity, $\mathrm{pH}$, release of calcium ions, and flow of a bioceramic root canal sealer. J Endod 2012; 38:842-845.

27. Majeed A, AlShwaimi E: Push-out bond strength and surface microhardness of calcium silicate-based biomaterials: an in vitro study. Med Princ Pract 2017; 26: 139-145.

28. 28. Cohen BI, Volovich Y, Musikant BL, Deutsch AS. The effects of eugenol and epoxy-resin on the strength of a hybrid composite resin. J Endod. 2002; 28(2):79-82.

29. Cecchin D, Farina AP, Souza MA, Carlini-Junior B, Ferraz CC. Effect of root canal sealers on bond strength of fibreglass posts cemented with self-adhesive resin cements. Int Endod J 2011;44:314-320.

30. Elnaghy AM: Effect of QMiX irrigant on bond strength of glass fiber posts to root dentine. Int Endod J 2015; 47: 280-289.

31. Cecchin D, Farina AP, Galafassi D, Barbizam JV, Corona SA, Carlini-Júnior B (2010) Influence of sodium hypochlorite and EDTA on themicrotensile bond strength of a self-etching adhesive system. J Appl Oral Sci 18:385-389.

32. kelea A and Koseaglo M : Dissolution of root canal sealers in EDTA and $\mathrm{NaOCl}$ solutions journal of the American Dental Association. 2009; 140(1):74-9. 
33. Garrib and Camiller j: retreatment efficacy of hydraulic calcium silicate sealers used in single cone obturation.: $\mathrm{j}$ dent. 2020

34. De Groot SD, Verhaagen B, Versluis M, et al: Laseractivated irrigation within root canals: cleaning efficacy and flow visualization. Int Endod J. 2009; 42: 1077-1083

35. Garcia L, Naves LZ, Farina AP, Walker CM, Consani S, De Carvalho Panzeri Pires-Desouza F. The effect of a 980 $\mathrm{nm}$ diode laser with different parameters of irradiation on the bond strength of fiberglass posts. Gen Dent. 2011; 59: $31-37$

36. Strefezza C et al: Effect of 830nm Diode Laser Irradiation of Root Canal on Bond Strength of Metal and Fiber Post Photomedicine and Laser Surgery2018; Volume XX, Number XX, .

37. Kaplowitz GJ. Effect of temperature on rectified turpentine oil as a gutta-percha solvent. J Endod 1994; 20: 173.

38. Olivi AP, Crippa R, Iaria G, Kaitsas V, DiVito E, Benedicenti S. Laser in endodontics (Part 1). Roots 2011;1: 1-5.

39. Pearson GJ, Macdonald AV. Use of infrared and ultraviolet lasers in the removal of dental hard tissue. Lasers Med Sci. 1994; 9: 227-37.

40. Boulnois JL. Photophysical processes in recent medical laser developments: A review. Laser Med Sci. 1986; 1: 47-66.

41. SukM et al. The efficacy of photon-initiated photoacoustic streaming in the removal of calcium silicate-based filling remnants from the root canal after rotary retreatment Lasers Med Sci.2017; 32:2055-2062.

42. Horvath SD, Altenburger MJ, Naumann M, Wolkewitz M, Schirrmeister JF. Cleanliness of dentinal tubules following gutta-percha removal with and without solvents: a scanning electron microscopic study. Int Endod J. 2009; 42(11):1032-1038.

43. Teixeira CS, Silva-Sousa YT, Sousa-Neto MD Bond strength of fiber posts to weakened root after resin restoration with different light-curing times. J Endod; 2009, 35:1034- 1039 .

44. Gaston BA, West LA, Liewehr FR, Fernandes C, Pashley DH Evaluation of regional bond strength of resin cement to endodontic surfaces. J Endod; 2001, 27:321-324

45. Ferrari M, Mannocci F, Vichi A, Cagidiaco MC, Mjör IA Bonding to root canal: structural characteristics of the substrate.Am J Dent ; 2000; 13:255-260

46. Manicardi CA, Versiani MA, Saquy PC, Pécora JD, SousaNeto MD Influence of filling materials on the bonding interface of thin-walled roots reinforced with resin and quartz fiber posts. J Endod. 2011; 37:531-537.

47. Mjör IA, Nordahl I .The density and branching of dentinal tubules in human teeth. Arch Oral Biol. 1996; 41:401-412.

48. Santos G et al: Influence of different endodontic sealers on bond strength of fiber posts to weakened roots after resin restoration; Clinical Oral Investigations, published 2021https://doi.org/10.1007/s00784-020-03744-0. 